\title{
Association between accepting the illness and effective insulin administration in patients with type 2 Diabetes Mellitus
}

ŞENGÜL KORKMAZ BINAY ( $\sim$ devrimbinay@hotmail.com )

Erzincan Binali Yildirim University: Erzincan Binali Yildirim Universitesi https://orcid.org/0000-00021541-3188

\section{Türkinaz AŞTI}

Bezmialem Vakif University: Bezmialem Vakif Universitesi

Keywords:

Posted Date: April 7th, 2021

DOI: https://doi.org/10.21203/rs.3.rs-396388/v1

License: (c) (i) This work is licensed under a Creative Commons Attribution 4.0 International License.

Read Full License 


\section{Abstract}

The authors have requested that this preprint be removed from Research Square. 